period and a mean of 188.0 per minute during the FR 9 sessions. S 2 emitted a mean of 149.6 words per minute during her baseline period and a mean of 156.6 during the FR 9 condition. Thus, it was the critical response that was being markedly affected by the reinforcement, and not overall speech rate.

\section{REFERENCES}

COHEN, B. D., KALISH, H., THURSTON, J. R., \& COHEN, E. Experimental manipulation of verbal behavior. Journal of Experimental Psychology, 1954, 47, 101-110.

DINOFF, M., RICHARD, H. C., SALZBERG, H., \& SIPPRELLE, C. N. An experimental analogue of three psychotherapeutic techniques. Journal of Clinical Psychology, $1961,62,608-609$.

GREENSPOON, J. The reinforcing effect of two spoken sounds on the frequency of two responses. American Journal of Psychology, $1955,68,409-416$.

GROSSMAN, D. An experimental investigation of a psychotherapeutic technique. Journal of Consulting Psychology, 1962, 16, 325-331.

HILDUM, D. C., \& BROWN, R. W. Verbal reinforcement and interview bias. Journal of Abnormal \& Social Psychology, 1956, 53, 108-111.

INCE, L. P. Effects of fixed-interval reinforcement on the frequency of a verbal response class in a quasi-counseling situation. Journal of Counseling Psychology, 1968a, 15, 140-146.

INCE, L. P. Modification of verbal behavior through variable interval reinforcement in a quasi-therapy situation. Behavior Research \& Therapy, 1968b, 6, 439-445.

MANDLER, G., \& KAPLAN, W. F. Subjective evaluation and reinforcing effect of verbal stimulus. Science, 1956, 124, 582-583.

ROGERS, J. M. Operant conditioning in a quasi-therapy setting. Journal of Abnormal \& Social Psychology, 1960, 60, 247-252.

SARASON, I. G. Interrelationships among individuals difference variables, behavior in psychotherapy and verbal conditioning. Journal of Abnormal \& Social Psychology, $1958,56,339.344$.

SIDMAN, M. Tactics of scientific research. Evaluating experimental data in psychology. New York: Basic Books, 1960.

WASKOW, I. E. Reinforcement in a therapy-like situation through selective responding to feeling or content. Joumal of Consulting Psychology, 1962, 26, 11-19.

\section{NOTES}

1. This study is based upon a dissertation submitted to the Graduate School of Florida State University in partial fulfillment of the requirements for the degree of Doctor of Philosophy.

2. Now at New York University Medical Center, Goldwater Memorial Hospital.

\title{
Free recall and organization as functions of paced or unpaced responding and presentation rate $^{1}$
}

\section{S. I. SHAPIRO and IRENE PONCE, The University of Hawaii, 2430 Campus Rd., Honolulu, Hawaii 96822}

Free recall and intertrial organization of unrelated words were assessed at presentation rates of $1 / 2,1,2$, or $4 \mathrm{sec}$, with recall either paced at 2-sec intervals or unpaced. Total recall times were equated for the two response modes. Neither recall nor organization differed for paced vs unpaced responding. Recall and organization were higher at slower presentation rates, and the two performance measures were positively correlated.

Ekstrand \& Underwood (1963) reported a small, but significant, superiority in free recall with unpaced, relative to paced, responding. As the authors noted, however, the amount of total recall time allotted to unpaced Ss $(60 \mathrm{sec})$ was greater than the total time allowed for paced Ss $(24 \mathrm{sec})$.
The present study was designed to determine if recall performance, and also intertrial organization, differ as a function of paced vs unpaced responding when total recall times are equated for the two types of responding. Relatively little attention has focused upon the relationship between presentation time and organization. Cofer, Bruce, \& Reicher (1966) found that category clustering (E-established organization) increased with slower presentation rates for a list of categorized words. The present study was, therefore, also directed to assessing the influence of presentation time upon the amount of S-generated intertrial organization for a list of unrelated words.

\section{MATERIALS}

A 16-item list was composed of the 15 words of Deese's (1959) List No. 9 and one additional word (note). Out of a possible 240 forward and backward interitem associations within the list, there were only two idiosyncratic associations and one of
$8 \%$ in a set of normative free-assocation data consulted. ${ }^{2}$ The Thorndike-Lorge (1944, $G$ count) word frequencies of 10 of the words were $A A$ or $A$, and the frequencies of the remaining words ranged from 2 to 49 occurrences per million words.

\section{PROCEDURE}

Twelve trials were given on a memory drum, each trial consisting of a different random order, with the restriction that no word appear twice in the same serial position and that no word be preceded or followed by another word more than once. A 2 by 4 factorial design was used with two testing methods (paced or unpaced) and four levels of presentation rate $(1 / 2,1$, 2 , or $4 \mathrm{sec}$ ). The $\mathrm{Ss}$ of all groups were given free-recall instructions that stressed that only the number of words recalled was important and not the order of their recall. The four groups of paced Ss were told additionally that they would hear a series of tape-recorded signals immediately after each presentation period and to write down a recalled word each time they heard a signal. If unable to recall a word for a given signal, the paced Ss were told to wait for the next signal and then to try again. The paced Ss were admonished to respond only upon hearing a signal and $E$ monitored their compliance with this task. The pacing was at the rate of $2 \mathrm{sec}$ per word for a total recall period of $32 \mathrm{sec}$. The pacing signals were recorded on magnetic tape from an audio signal generator at 2-sec intervals and consisted of a $925-\mathrm{Hz}$ tone of $1 / 10 \mathrm{sec}$ duration. The four groups of unpaced Ss were given a 32-sec recall period for each trial, which was found to be sufficient time for $S$ s to complete responding. Each $\mathrm{S}$ was given 12 lined response sheets that were kept face down until a recall period began when one sheet was turned over to record responses. At the conclusion of each recall period, the response sheet just used was placed out of sight, and a new trial began immediately. \section{SUBJECTS}

The Ss were 200 native English-speaking volunteers from introductory psychology classes at The University of Hawaii. The data of an additional 9 Ss were eliminated for apparatus failures or procedural errors. The experimental conditions were randomized in blocks of eight, with $25 \mathrm{Ss}$ assigned per condition. Approximately half of the $25 \mathrm{Ss}$ in each group were of each sex. The Ss were tested individually or in pairs. No $S$ had participated in a prior free-recall experiment.

\section{RESULTS AND DISCUSSION}

Table 1 presents the mean performance per trial for each group in terms of recall, intertrial organization, intrusions, and 
Table 1

Mean Performance Per Trial for Each Experimental Group

\begin{tabular}{|c|c|c|c|c|c|c|c|c|}
\hline \multirow{2}{*}{$\begin{array}{c}\text { Performance } \\
\text { Measure }\end{array}$} & \multicolumn{4}{|c|}{$\begin{array}{l}\text { Paced } \\
\text { Presentation Rate (Sec) }\end{array}$} & \multicolumn{4}{|c|}{$\begin{array}{c}\text { Unpaced } \\
\text { Presentation Rate (Sec) }\end{array}$} \\
\hline & $1 / 2$ & 1 & 2 & 4 & $1 / 2$ & 1 & 2 & 4 \\
\hline $\begin{array}{l}\text { Recall } \\
(\mathrm{O}-\mathrm{E}) \text { ITR } \\
\text { Intrusions } \\
\text { Duplicates }\end{array}$ & $\begin{array}{l}9.08 \\
0.43 \\
0.23 \\
0.20\end{array}$ & $\begin{array}{l}8.96 \\
0.31 \\
0.47 \\
0.32\end{array}$ & $\begin{array}{r}10.23 \\
0.53 \\
0.07 \\
0.34\end{array}$ & $\begin{array}{r}10.76 \\
0.97 \\
0.14 \\
0.24\end{array}$ & $\begin{array}{l}8.63 \\
0.44 \\
0.35 \\
0.23\end{array}$ & $\begin{array}{l}9.30 \\
0.59 \\
0.17 \\
0.24\end{array}$ & $\begin{array}{l}9.94 \\
0.51 \\
0.10 \\
0.19\end{array}$ & $\begin{array}{r}10.48 \\
1.10 \\
0.15 \\
0.16\end{array}$ \\
\hline
\end{tabular}

duplicate responses. Intrusions and duplicate responses were omitted in computing recall and organization. A 2 by 4 by 12 (Response Mode by Presentation Rate by Trials) analysis of variance applied to the recall data revealed that the main effect of presentation rate was significant $[F(3,192)=14.55$, $\mathrm{p}<.001]$, indicating that slower presentation rates resulted in higher levels of recall. Recall increased over trials $[F(11,2112)=299.23, \mathrm{p}<.001]$ but did not differ for paced vs unpaced responding $[F(1,192)<1]$. None of the interactions approached significance. Individual comparisons employing the Duncan multiple-range test indicated that recall at the 2- and 4-sec rates was significantly superior to recall at the $1 / 2-$ or $1-\mathrm{sec}$ rates $(\mathrm{p}<.01)$.

The measure of intertrial organization employed was Bousfield \& Bousfield's (1966) observed minus expected intertrial repetitions, $\mathrm{O}-\mathrm{E}$ (ITR), modified to take account of bidirectional organization (Gorfein, Blair, \& Rowland, 1968). A 2 by 4 by 11 (Response Mode by Presentation Rate by Successive Trial Pairs) analysis of variance revealed that the main effect of intertrial organization was significant $[F(3,192)=5.92, p<.001]$, indicating that slower presentation rates resulted in higher levels of organization. Organization significantly increased over trial pairs $[\mathrm{F}(10,1920)=14.05, \mathrm{p}<.001]$ but did not differ for paced vs unpaced responding $[F(1,192)<1]$. The only significant interaction was that of Presentation Rate by Trial Pairs $[F(30,1920)=1.82, p<.025]$; however, reduction of the degrees of freedom to provide a conservative test for a repeated measures design (Greenhouse \& Geisser, 1959) did not result in a significant interaction $[F(7,192)=1.82, \quad p<.10]$. The conservative test does not change the significance level of the main effect of trials $[F(1,192=14.05, p<.001]$. The Duncan multiple range test indicated that organization was significantly greater at the 4-sec rate relative to any of the slower rates $(\mathrm{p}<.01)$, among which there were no significant differences. Within each of the four presentation-rate conditions, a product-moment correlation was computed between mean recall and intertrial organization scores. The I values were +0.64 , +0.57, +0.60, and +0.96, respectively, for the $1 / 2-, 1-, 2-$, and $4-\mathrm{sec}$ presentation rates. The correlations were all significant at $p<.001$. The mean number of $(\mathrm{O}-\mathrm{E})$ ITRs per $\mathrm{S}$ for each of the eight experimental groups were all significantly larger than zero when analyzed by $t$ tests $(\mathrm{df}=24)$ at $\mathrm{p}<.01$ (two-tail) with one mean at $p<.05$. These results indicate that the amount of intertrial organization exceeded chance. The percentage of Ss in each of the eight groups with positive $(\mathrm{O}-\mathrm{E}) \mathrm{ITR}$ scores ranged from $80 \%$ to $88 \%$, indicating that organization was not confined to a minority of Ss.

The intrusion and duplicate responses data were relatively infrequent. Intrusions rapidly decreased during the first few trials, and duplicate responses were slightly, but significantly, greater with paced responding.

The results indicate that there are no differences for paced vs unpaced responding in recall performance or intertrial organization when total recall time is equated. This relationship was reflected at each of the four presentation rates tested. Ekstrand \& Underwood (1963) employed a 2-sec presentation rate and pacing at $2 \mathrm{sec}$ per item, a situation that was replicated within the present study. It therefore appears that the superior recall performance for unpaced vs paced Ss reported by Ekstrand and
Underwood was probably due to the greater total recall time allowed for unpaced Ss than for paced Ss. It remains to be determined whether or not paced and unpaced recall also do not differ when response periods are varied as well as presentation intervals. Intertrial organization was significantly greater for the 4-sec presentation rate than for the three faster rates, suggesting that Ss make use of the additional time to organize items. Ekstrand and Underwood also suggested that the structure of recall may be different for paced vs unpaced Ss and that such a difference might be extracted by measuring organization. However, the similarity in the amount of intertrial organization exhibited by paced and unpaced $S s$ in the present study appears to support a common structure of recall. In addition, an analysis of the degree of commonality of the organizational units employed failed to reveal any notable differences between paced and unpaced responding.

OUSFIELD, A. K., \& BOUSFIELD, W. A. Measurement of clustering and of sequential constancies in repeated free recall. Psychological Reports, 1966, 19, 935-942.

COFER, C. N., BRUCE, D. R., \& REICHER, G. $M$. Clustering in free recall as a function of certain methodological variations. Journal of Experimental Psychology, 1966, 71, 858-866.

DEESE, $\mathbf{J}$. Influence of inter-item associative strength upon immediate free recall. Psychological Reports, 1959, 5, 305-312.

EKSTRAND, B., \& UNDERWOOD, B. J. Paced versus unpaced recall in free learning. Journal of Verbal Learning \& Verbal Behavior, 1963, 2, 288-290.

GORFEIN, D. S., BLAIR, C., \& ROWLAND, C. The generality of free-recall: 1 . Subjective organization as an ability factor. Psychonomic Science, 1968, 11, 279-280.

GREENHOUSE, S. W., \& GEISSER, S. On methods in the analysis of profile data. Psychometrica, 1959, 24, 95-112.

THORNDIKE, E. L., \& LORGE, I. The teacher's word book of 30,000 words. New York: Bureau of Publications, Teachers College, Columbia University, 1944 NOTES

1. This research was supported by a grant from The University of Hawaii Research Council to the first author and was conducted during the second author's tenure as an East-West Center Grantee of The University of Hawaii. Preparation of this report was facilitated by the services of The University of Hawaii Statistical and Computing Center and the Social Science Research Institute. Craig S. Kowalski assisted in analyzing the data. 2. James Deese, unpublished data. 